\title{
THE ROLE OF COMPUTER SKILLS ON THE OCCUPATION LEVEL
}

\author{
Brian Fabo ${ }^{1,2}$, Martin Kahanec ${ }^{3,4,5,6}$ \\ ${ }^{1}$ National Bank of Slovakia, Bratislava, Slovakia \\ ${ }^{2}$ Comenius University, Bratislava, Slovakia \\ ${ }^{3}$ Central European University, Vienna, Austria \\ ${ }^{4}$ Central European Labour Studies Institute, Bratislava, Slovakia \\ ${ }^{5}$ University of Economics, Bratislava, Slovakia \\ ${ }^{6}$ Global Labor Organization, Essen, Germany
}

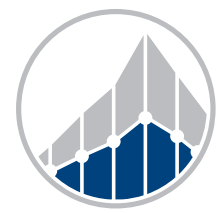

EUROPEAN JOURNAL OF BUSINESS SCIENCE AND TECHNOLOGY

Volume 6 Issue 2 ISSN 2694-7161 www.ejobsat.com

\begin{abstract}
This paper explores the question of computer skills applicability on individual occupation level in the Netherlands using two web-based data sources: the WageIndicator online survey and job vacancies posted online. The aim of this study is to explore these innovative data sources and compare the information obtained from them with the computer skill requirements inferred from the ISCO occupation classifications. Using the WageIndicator survey, we found a very high incidence of computer use reported by the holders of nearly all office occupations and a substantial degree of computer use by the holders of skilled manual occupations. With a partial exception of the unskilled work in elementary occupations, we find that Dutch job holders are very likely to use computers even in occupations, which are not associated with any relevant tasks. We were able to confirm the robustness of our finding by benchmarking our figures against the PIAAC survey. An older version of this article has been published as a dissertation chapter (Fabo, 2017).
\end{abstract}

\section{KEY WORDS}

digital skills, job matching, vacancies, WageIndicator

\section{JEL CODES}

$\mathrm{C} 81, \mathrm{~J} 24$

\section{INTRODUCTION}

Skill matching in the labor market is an important conceptual and policy issue. But to better measure skill mismatch and provide for improved labor market matching, we need to understand the interconnections between tasks, skills and occupations. Mapping these connections is however costly, when conducted by occupations experts, as it requires considerable expertise and time. Some attempts have been made to measure this mapping using new data collection techniques that utilize data originating from the Internet (Beblavý et al., 
2016b; Fabo and Tijdens, 2014; Visintin et al., 2015). Each of these attempts was based on a single web-based data source, mapping either the supply side or the demand side. A pioneering, and thus far single, attempt to compare the supply and demand side using web data looked at education requirements only (Tijdens et al., 2018). In this paper, we look specifically at the highly policy relevant aspect of computer skills supply and demand across occupations utilizing two distinct data sources - the WageIndicator web survey and job vacancies posted online.

The need to measure the demand for skills and occupational skill requirements is currently quite salient due to the continued coexistence of high unemployment and growing numbers of hard-to-fill vacancies in Europe. According to Eurostat, a large proportion of Europeans, particularly young Europeans, struggle to even enter the labor market. In 2019, approximately $14 \%$ of Europeans aged 15-34 years were classified as not in education, employment, or training (NEET) and this number has dropped only slightly in spite of the robust recovery in the European labor markets in the late 2010s. The situation is particularly pronounced in Italy, where the NEET rate peaks at approximately $24 \%$. Meanwhile, $33 \%$ of employers indicated they struggle to attract applicants with the right skills (Eurostat, 2010). According to the European Skills and Jobs (ESJ) survey, there remains a high degree of skills and qualifications mismatch (CEDEFOP, 2015).

Based on the European Skills and Jobs (ESJ) survey, in 2014, 25\% of highly qualified employees were overqualified for the job. Whilst the taking of a job requiring a lower level of qualification than is held by the applicant can be a personal preference, the same survey also found that $27 \%$ of employees are stuck in the socalled 'dead end' jobs; that is in positions that do not allow the workers to develop their skills and improve their productivity (CEDEFOP, 2015). Furthermore, a large proportion of Europeans, particularly young Europeans, struggle to even enter the labor market, according to Eurostat.
Economists have long considered the role of skills central to the understanding of the matching between employees and employers in the labor market, but also from the policy perspective. Of particular importance is the human capital approach, which has become widely accepted in economics (Becker, 1962; Benhabib and Spiegel, 1994; Schultz, 1971). According to this approach, highly skilled workers are more productive and thus more valuable for employers. Unskilled workers, on the other hand, are not as productive and thus are offered only lower wages or less favorable working conditions. They may not be hired at all, if, for example, a minimum wage policy makes their employment economically unsound.

But how can a situation where workers underutilize their skills on a large scale coexist with skills shortages perceived by employers? Empirical research shows that the likely reason is a shortage of specific skills in high demand by employers (CEDEFOP, 2014). Being able to identify the demand for skills is thus crucial for informing policy makers in particular in areas such as education and training. Beblavý et al. (2016c) study IT skill demand based on a large sample of job vacancies posted online throughout 2013 for 30 common occupations in the USA. They found that (i) demand for computer skills is high across most occupations and growing as the complexity of an occupation increases, (ii) while there are many different computer skills, only a relatively small number of them is relevant for workers outside of the IT industry itself, (iii) computer skills determined on the basis of job vacancies are highly in line with the computer skills inferred from tasks defined for the individual occupations in occupational classification systems ISCO.

These findings potentially open doors for using web data to better understand the mapping between skills, tasks and occupations, and inform policy in a wide range of areas connected to skill acquisition and use. In particular, webbased data collection techniques may help us gauge information about the usefulness of skills across occupations and thus provide for enhanced policies aiming at improved skill matching in the labor market. However, the scope and 
usefulness of web-based data for classification of jobs and tasks pertaining thereto has yet to be tested. In this paper, we extend Beblavý et al. (2016c) in this direction by (i) benchmarking the job vacancy data against web-based survey data with respect to expert mapping of tasks to occupations and by (ii) looking at a wider scope of occupations at all skill levels.

\section{THEORETICAL FRAMEWORK}

Studying labor market matching is a complicated matter, because the universe of jobs and tasks that workers do, and skills they have, is large, complex and dynamic (Beblavý et al., 2016a; Fabo and Tijdens, 2014; Visintin et al., 2015). In this section, we zoom in on the current state of the art with regards to ways to systematically study the phenomenon. Jobs can be aggregated into a smaller number of clusters by abstracting from the context of work and focusing purely on the tasks performed by the workers in those jobs. These groups, called occupations, can be defined as follows: "An occupation is a bundle of job titles, clustered in such a way that survey respondents will recognize it as their job title in a valid way; an occupation identifies a set of tasks distinct from another occupation; an occupation should have at least a non-negligible number of jobholders and it should not have an extremely large share in the labor force" (Tijdens, 2010).

This aggregation of jobs is done both for practical reasons - to better organize labor (Damarin, 2006) and for research purposes - to understand skill demands on the labor market (Levenson and Zoghi, 2010). Employers and employees use occupations to characterize and refer to jobs. The skill dimension is inseparable from tasks, because a skill is "a worker's endowment of capabilities for performing various tasks" (Acemoğlu and Autor, 2011). Consequently, a salient aggregation of jobs into occupations is necessary for our understanding of the matching between employers and employees in the labor market.

Skills can be generally split into two categories: job specific and transferable. For example the $\mathrm{O}^{*} \mathrm{NET}$ classification of occupations, used widely in the US considers the "content" and "process" skills to be job specific and "social skills", "technical skills", "complex problem- solving skills", "systems skills" and "resource management skills" to be transferable. Computer skills can be placed in both categories (BGT, 2015) as they can act as the "content" of the job particularly in the IT occupations, but also can be regarded as a technical skill increasing the productivity of non-IT workers. Recently, empirical evidence has underlined the importance of the transferable dimension of computer skills across the entire labor market, including some of what was traditionally considered low skill occupations (Beblavý et al., 2016c, 2016d). Scholars along with the policy makers started recognizing exclusion from the labor market faced by workers lacking computer skills (Bührer and Hagist, 2017; CEDEFOP, 2015; Horrigan, 2016; Smith, 2015). Consequently, it appears pertinent to analyse the role of computer skills in non-IT occupations as well.

There are several approaches for determining the demand and supply for IT skills on a labor market:

The most obvious approach is connected with the occupations themselves. Because occupations are defined through tasks and tasks imply skills, it is possible to infer skills demand from the tasks associated with the individual occupations. Individual classifications of occupations, such as the International Standard Classification of Occupations (ISCO) or the American $\mathrm{O}^{*} \mathrm{NET}$ classification defines each occupation on the basis of a list of tasks assigned to it by labor market experts (Elias, 1997). The downside is that such systems are only rarely updated. For example the last update of ISCO took place in 2008, which was preceded by the 1988 update; overall there has been only four updates of the classification since the first version in 1958. Meanwhile, the nature of work is quickly changing due to numerous factors, including technological 
progress, outsourcing/offshoring and change in labor organization (Acemoğlu and Autor, 2011; Beblavý et al., 2016a; Cowen, 2013).

Fortunately, it is not always necessary to rely on experts. Skill and task questions have increasingly been included in surveys such as the OECD Adult Skills survey PIAAC and the web-based WageIndicator survey (Fabo and Tijdens, 2014). Importantly, the evaluation of job requirements by the job holder has been found to be largely consistent with the expert estimates, even in the case of non-representative web surveys (Tijdens et al., 2014, see the data section for our own robustness check). Such web survey-based estimates of computer skill applicability can be thus used for economic analysis (Mýtna Kureková et al., 2015; Tijdens and Visintin, 2016; Visintin et al., 2015; Drahokoupil and Fabo, 2020). In particular, the large scale, continuous web-based surveys provide up to-date-information and are usable for reliable exploratory analysis, especially if the results can be benchmarked against a representative data source on a regular basis (Fabo and Kahanec, 2018; Steinmetz et al., 2014; Tijdens and Steinmetz, 2016).

Additionally, it is possible to learn from employers. That is, because when hiring, employers tend to think of the task list the worker needs to be able to perform (Autor, 2001; Winterton, 2009). Furthermore, the Internet is increasingly becoming a place, where job vacancies are advertised and thus an important source of data on skill demand (Askitas and Zimmermann, 2015; Beblavý et al., 2016c, 2016d; Lenaerts et al., 2016; Mýtna Kureková et al., 2015; Fabo et al., 2017). Just like in the case of web surveys, there is some controversy associated with the use of these new data sources for social science research. Nonetheless, in spite of significant concerns pertaining to mainly the representativeness and the potential for generalization of results generated on the basis of this data source, there is a growing consensus among scholars that web-based data are going to be increasingly important source for the research on the labor market (Askitas and Zimmermann, 2015).

This paper scrutinizes these two approaches to mapping tasks to occupations - web surveybased and vacancy-based - to test these methodologies in terms of their precision as benchmarked to expert-based mapping. It this sheds more light on possible approaches that can help to address the need for a more precise and up-to-date efficient mapping of tasks to occupations in the rapidly developing and changing labor market.

\section{METHODOLOGY AND DATA}

\subsection{Data Description}

This paper analyses skill requirements inferred from three data sources: (i) the tasks assigned to the individual occupations by labor market experts in the ISCO2008 classification of occupations, (ii) the self-reported use of computer skills as measured by the WageIndicator survey and (iii) the share of an explicit IT requirements in vacancies posted on the Internet. Due to the availability of data, we focus on the Netherlands, as explained later in this section.

The survey-based data we obtained from the WageIndicator survey, which is a continuous, large scale, voluntary web survey covering more than 90 countries on all continents. Nonethe- less, the quality of the data varies among countries. $18 \%$ of all data intake is collected in the Netherlands, where the survey originally started and where the local website hosting the survey gets approximately five million unique visitors per year. The high number of respondents to the survey in the Netherlands and the fact that Internet use is very widespread in the country result in a sample, which is quite similar to general population sample, and suitable for exploratory analysis (Fabo and Kahanec, 2018).

In the WI survey, we added a module asking employees about their use of computers at work. Specifically, we asked "When do you use a computer or tablet?" with possible answers being 


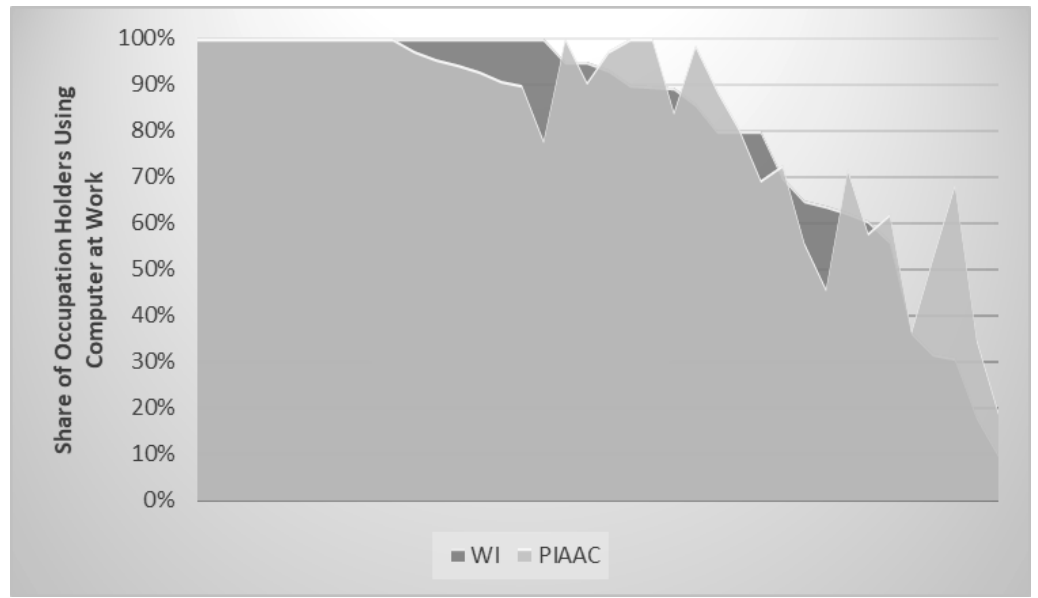

Fig. 1: Comparison of self-reported computer use per occupation between WageIndicator and PIAAC datasets

(i) Only during working hours (ii) Both during working hours and free time (iii) Only during free time (iv) Never. We have recoded these questions such that if a respondent selected either option (i) or (ii), they are considered as someone using a computer at work, otherwise we consider them a non-user.

We launched the module on the 18th of August, 2016 and collected the data until the end of the year. The respondents were not obliged to answer the questions to proceed with the questionnaire. We only used the occupations for which at least ten respondents answered the IT module. Within less than five months, we managed to cover 62 occupations (out of a total of 436 occupations defined in ISCO2008), with a total of 1644 responses, covering all aggregated occupations groups (one digit ISCO), except for military occupations and skilled workers in agriculture. As a result, our analysis is limited to common occupations and might not be representative of occupations with few holders, which is a widespread general problem in occupations research (Tijdens et al., 2014).

To get a sense of the representativeness of our data, we compare it against a representative data source, the Dutch Survey of Adult Skills (PIAAC), which is organized by OECD. One limitation is that the PIAAC data were collected in the years 2011 and 2012, so there is a 5-year asynchrony. A further limitation is that when we applied the same criterion as with the WageIndicator data and eliminated all occupations with less than 10 observations, we could only match 49 out of the 62 occupations, which are sufficiently covered in both datasets. Both datasets exhibit a largely similar picture for nearly all office jobs holders who show a very high intensity of computer use at work, while the percentage of those using computers is lower among the holders of manual jobs. The correlation between the two indicators is highly significant and very strong $(r=0.922$, also see Fig. 1). Statistically, we can also compare the two sets of estimates using a paired $t$-test for two sets of estimates. This test is statistically insignificant with a $t$ value of $t=-0.8719$ ( $p=$ $0.806)$. Where we see differences, these typically reflect a large growth of use of computers at work by some manual job holders, such as electrical mechanics, truck and taxi drivers, cooks or carpenters.

Vacancy-based data on the share of computer skills in occupations were obtained from job vacancies posted online between August and December 2016. The dataset was provided by the company Textkernel, which is the market leader in the collection, processing and analysing job vacancy data in western Europe utilizing a large number of advanced algorithms to get as representative sample of job vacancies as possible, with by far the most complete dataset being collected in the Netherlands (Zavrel, 2016). The sample covers 60 of the 
analysed occupations and is based on nearly 300,000 unique job vacancies posted online. In line with our previous analysis (Beblavý et al., 2016c), we calculate the share of vacancies containing at least one keyword associated with computer use within occupations defined at the most detailed (4-digit) level of ISCO occupations classification.

The Dutch labor market represents an ideal environment to explore the use of online data because it contains a very high quality online survey as well as a near-exhaustive database of online job vacancies. Furthermore, the Netherlands has a large high-skilled workforce and a high degree of computerization, which makes the market for computer skills broad enough and deep enough to get a sufficient number of observations for a large-enough number of occupations. Finally, the Dutch labor market is relatively homogenous with limited a degree of regional variations, making it particularly suitable for an analysis of occupations within the country.

\subsection{Analytical Strategy}

The aim of our analysis is to evaluate what the two online data sources can tell us about the intensity of computer skill use across occupations in the Dutch labor market. A key question is how we can decide which of the mappings is more accurate. After all, two things are being measured - the demand by employers And the self-reported use of skills by workers. Our strategy rests in the ISCO occupational classification itself and on the information it contains about skill use intensity across individual occupations. There are two distinct pieces of information to be identified:

First, we looked at the relevance of computer skills for the tasks associated with individual occupations in the ISCO classification. We have coded a total of 466 individual tasks such that each was either classified as clearly requiring a computer (for instance "Developing and implementing software and information system testing policies, procedures and scripts") or not necessarily requiring computer skills, but having use for them (such as "Designing and modifying curricula and preparing courses of study in accordance with requirements", which can still be performed using pen or paper, but is likely done using a text processing software by most educators) and those, that have no use for computer skills at all (such as "Maintaining discipline and good working habits in the classroom"). For coding, we included two typical uses of computer applications identified in a previous job vacancy analysis (Beblavý et al., 2016b) - general computer use, including using job-specific software and office applications such as spreadsheet and text processor.

Second, we used information on occupation complexity. The ISCO classification also associates occupations with the concept of complexity of tasks involved by sorting each civilian occupation into one of nine aggregated occupation groups plus an additional group for military occupations, which are not a subject of analysis in this paper. Eight out of those groups can be connected to degrees of complexity of tasks associated with them. The most complex, professional, occupations belong to Group 2 . Groups 3-8 contain occupations with an intermediate degree of complexity, with groups 3 and 4 containing office jobs, and groups 5-8 containing manual labor. Finally, Group 9 contains elementary occupations with a low complexity of associated tasks. Group 1 is more heterogeneous than the other ones, by virtue of containing managerial occupations, which are generally associated with an intermediate to high degree of complexity (Hunter, 2009; Mýtna Kureková et al., 2013), making it impossible to exclusively assign this group to a specific complexity level.

In the analysis, we use these occupation traits determined by labor market experts when constructing the ISCO classification as a guide. More precisely, we defined three distinct groups of occupations: Those that require computer skills to perform at least one of the tasks associated with them, those that do not have any apparent use of the computer skills and finally, those that do not necessarily require the computer skills, but entail tasks, which might be performed more efficiently using a computer. Similarly, we looked at the occupation complex- 
ity to see the demand and use of computer skills across manual and office/service occupations with various levels of complexity.

We then compare the (i) measured demand for computer skills determined on the basis of actual job vacancies ${ }^{1}$, (ii) the use of computers reported by occupation holders, and (iii) the expert-based mapping of skills to occupations based on the ISCO classification. Based on these three sources, we establish a multi-dimensional picture of the role of the IT skills in the contemporary Dutch labor market and shed light on their use and measurement options.

\section{RESULTS}

Having described our analytical tools and data, we are now ready to proceed with the presentation of the results. This section is organized on the basis of the ISCO classification, first looking at occupations on the basis of the applicability of computer skills inferred from tasks associated with them.

Through coding of tasks, we have identified 17 occupations, a mixture of professional and administrative occupations, which require the use of a computer for at least one task associated with them. As can be seen in Tab. 1, all or nearly all holders of these occupations use computers at work. Nonetheless, when looking at the vacancies, we see these high skill occupations (including several in IT, such as computer network professionals, which cannot be performed without computer skills) do not explicitly ask for computer skills in the majority of the cases. This likely follows from the fact that not all skill requirements are explicitly specified, because they are sometimes taken for granted. That would explain why the demand for computer skills surges for administrative occupations, such as secretaries, where those skills are not necessarily taken for granted. Nonetheless, if we accept this explanation, it strengthens the case for skepticism towards the use of job vacancies to determine the applicability of specific skills, as the scope of tendency of employers leaving out some skill requirements they take for granted is clearly a major concern (Mýtna Kureková et al., 2016).
Shifting our attention to thirteen manual occupations, both skilled and unskilled, which have no apparent use for computer skills according to tasks associated with them, a large share of workers (but certainly not all of them) in these occupations uses a computer (Tab. 2). Of particular interest are Healthcare assistants, out of whom nearly $90 \%$ use a computer, as well as Stationary plant and machine operators, Motor vehicle mechanics and repairers, which are all above $70 \%$. This suggests a major shift of nature of those occupations as they now require skills not foreseen when constructing the 2008 update of the ISCO classification. The appearance of new tasks in existing occupations has been observed in the labor studies literature and is a common manifestation of a shifting skill demand (Barley and Tolbert, 1991; Beblavý et al., 2016a; Crosby, 2002) Turning to job vacancies, we see that demand for computer skills in these occupations is in general lower than for occupations that entail tasks associated with computer skills.

The information we can learn from job vacancies is, meanwhile, much more limited and does not match the story inferred from the WI survey. The explicit requirement for computer skills in vacancies recruiting for these jobs is negligible and does not allow us to identify the uptick in demand for computer skills in some occupations, something which is evident from the WageIndicator data.

\footnotetext{
${ }^{1}$ After having experimented with various computer skills definition from different sources while working with the US data (Beblavý et al., 2016b), we found the regular expression ((MS|Microsoft) Excel)|((MS|Microsoft) excel)|((MS|Microsoft) Word)|((MS|Microsoft) word)|((MS|Microsoft) Office)|((MS|Microsoft) office)| $(\mathrm{PC}) \mid$ (Computer) the best to estimate the IT skills requirement. Luckily, the Dutch word for computer is the same as the English one, so the regular expression was usable also with the vacancies in Dutch.
} 
Tab. 1: Applicability of computer skills for occupations requiring computer skills

\begin{tabular}{lcc}
\hline Occupation & $\begin{array}{c}\text { Vacancies requiring } \\
\text { computer skills }\end{array}$ & $\begin{array}{c}\text { Respondents reporting } \\
\text { using computer in the WI survey }\end{array}$ \\
\hline Secretaries (general) & $25 \%$ & $94 \%$ \\
General office clerks & $17 \%$ & $99 \%$ \\
ICT professionals & $16 \%$ & $100 \%$ \\
Accounting and bookkeeping clerks & $16 \%$ & $100 \%$ \\
Personnel clerks & $15 \%$ & $96 \%$ \\
Contact centre information clerks & $14 \%$ & $100 \%$ \\
Systems analysts & $10 \%$ & $100 \%$ \\
Advertising and marketing professionals & $9 \%$ & $100 \%$ \\
Computer network professionals & $9 \%$ & $100 \%$ \\
Industrial and production engineers & $8 \%$ & $100 \%$ \\
Accountants & $8 \%$ & $100 \%$ \\
Applications programmers & $8 \%$ & $100 \%$ \\
Software and applications developers & $8 \%$ & $100 \%$ \\
Statistical, finance and insurance clerk & $8 \%$ & $98 \%$ \\
Accounting associate professionals & $7 \%$ & $100 \%$ \\
Draughtspersons & $6 \%$ & $100 \%$ \\
Graphic and multimedia designers & $4 \%$ & $96 \%$ \\
\hline
\end{tabular}

Tab. 2: Applicability of computer skills for occupations with no apparent use for computer skills

\begin{tabular}{lcc}
\hline Occupation & $\begin{array}{c}\text { Vacancies requiring } \\
\text { computer skills }\end{array}$ & $\begin{array}{c}\text { Respondents reporting } \\
\text { using computer in the WI survey }\end{array}$ \\
\hline Stationary plant and machine operators & $5 \%$ & $76 \%$ \\
Health care assistants & $3 \%$ & $89 \%$ \\
Electrical mechanics and fitters & $3 \%$ & $56 \%$ \\
Freight handlers & $3 \%$ & $65 \%$ \\
Motor vehicle mechanics and repairers & $2 \%$ & $80 \%$ \\
Fitness and recreation instructors & $2 \%$ & $73 \%$ \\
Child care workers & $1 \%$ & $31 \%$ \\
Cooks & $1 \%$ & $61 \%$ \\
Waiters & $1 \%$ & $32 \%$ \\
Car, taxi and van drivers & $1 \%$ & $64 \%$ \\
Domestic cleaners and helpers & $1 \%$ & $10 \%$ \\
Carpenters and joiners & $0 \%$ & $18 \%$ \\
Heavy truck and lorry drivers & $0 \%$ & $36 \%$ \\
\hline
\end{tabular}

This leaves us with a group of 32 occupations, containing professional and administrative occupations, service and sales occupations and even some skilled manual occupations. Occupations in this group do not require computer skills, but entail tasks, which can be potentially performed more efficiently (Tab. 3). In most such occupations, the use of computers is universal or nearly universal. While there are still some occupations, such as Shop assistants, Primary school teachers or Building and related electricians, which still employ a substantial portion of workers who do not use computers at work, even in those occupations, a vast majority of workers benefit from computers. Interestingly, the requirement for computer skills in 
Tab. 3: Applicability of computer skills for occupations with possible, but not necessary, use for computer skills

\begin{tabular}{|c|c|c|}
\hline Occupation & $\begin{array}{l}\text { Vacancies requiring } \\
\text { computer skills }\end{array}$ & $\begin{array}{l}\text { Respondents reporting } \\
\text { using computer in the WI survey }\end{array}$ \\
\hline Administrative and executive secretaries & $27 \%$ & $100 \%$ \\
\hline Receptionists (general) & $24 \%$ & $90 \%$ \\
\hline Production clerks & $19 \%$ & $100 \%$ \\
\hline Buyers & $14 \%$ & $100 \%$ \\
\hline Business services and admin. managers & $11 \%$ & $90 \%$ \\
\hline Human resource managers & $10 \%$ & $100 \%$ \\
\hline Product graders and testers (except food) & $10 \%$ & $91 \%$ \\
\hline Sales and marketing managers & $9 \%$ & $100 \%$ \\
\hline Management and organization analysts & $9 \%$ & $100 \%$ \\
\hline Commercial sales representatives & $9 \%$ & $95 \%$ \\
\hline Journalists & $8 \%$ & $100 \%$ \\
\hline Stock clerks & $8 \%$ & $80 \%$ \\
\hline University and higher education teachers & $7 \%$ & $100 \%$ \\
\hline Managing directors and chief executives & $6 \%$ & $93 \%$ \\
\hline Personnel and careers professionals & $6 \%$ & $100 \%$ \\
\hline Enviro. and occup. health inspectors & $6 \%$ & $100 \%$ \\
\hline Legal professionals & $5 \%$ & $100 \%$ \\
\hline Employment agents and contractors & $5 \%$ & $100 \%$ \\
\hline Nursing professionals & $4 \%$ & $95 \%$ \\
\hline Policy administration professionals & $4 \%$ & $100 \%$ \\
\hline Construction supervisors & $4 \%$ & $100 \%$ \\
\hline Shopkeepers & $4 \%$ & $100 \%$ \\
\hline Agricultural and ind. mach. mechanics & $4 \%$ & $80 \%$ \\
\hline Vocational education teachers & $3 \%$ & $100 \%$ \\
\hline Social work and counselling professional & $3 \%$ & $100 \%$ \\
\hline Shop supervisors & $3 \%$ & $81 \%$ \\
\hline Shop sales assistants & $3 \%$ & $62 \%$ \\
\hline Building and related electricians & $3 \%$ & $70 \%$ \\
\hline Physiotherapists & $1 \%$ & $100 \%$ \\
\hline Primary school teachers & $1 \%$ & $86 \%$ \\
\hline Clerical support workers & $\mathrm{N} / \mathrm{A}$ & $92 \%$ \\
\hline
\end{tabular}

posted vacancies is explicitly stated only for a few administrative positions. Consequently, on the basis of the vacancy data, we would not be able to see how widespread the use of computer skills is in these occupations.

Finally, we consider the complexity of tasks (see the discussion in the analytical strategy section) associated with the individual occupations, rather than specifically the applicability of computer skills. The results based on the WI survey and vacancy data largely match the previous results as far as division between office and manual occupations is concerned. Regardless of tasks complexity, office and service jobs require computer skills more often than manual jobs.

However, new insights emerge when looking at the details. Based on the WI data we see that nearly all holders of office/service jobs use computers, while only about $60 \%$ of skilled manual workers do. Low-skilled employment is a specific category with less than $40 \%$ of workers using 


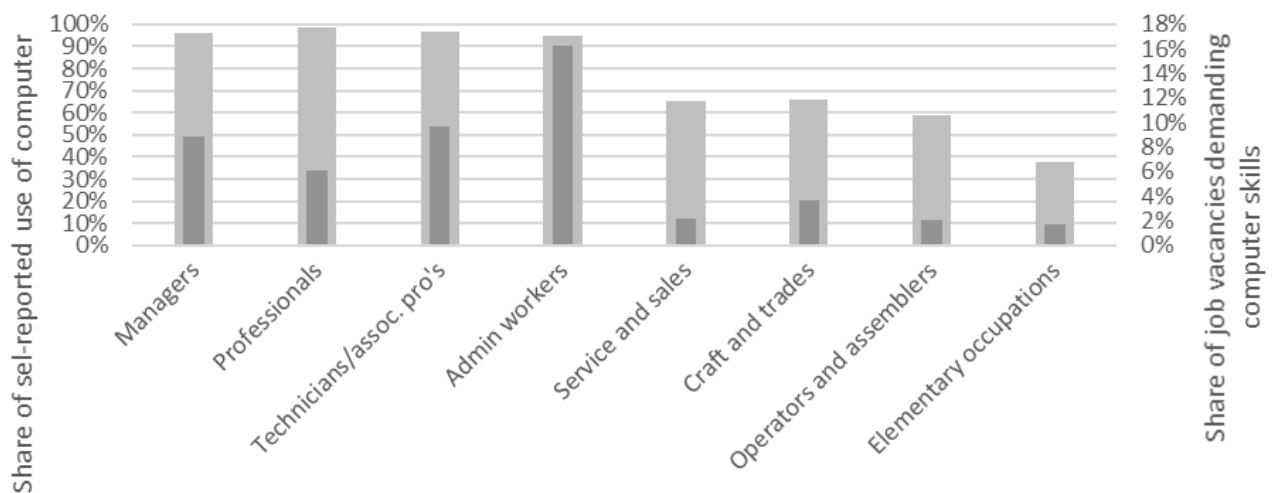

ISCO occupation group

WI Vacancies

Fig. 2: Average computer skills applicability per ISCO occupation group. Notes: Inferred from self-reported rates in the WI survey (left axis) and vacancies containing IT skill requirement (right axis)

a computer at work. The detailed story told by vacancies is different from the ones inferred from the WI survey, or indeed can be expected on the basis of complexity of tasks associated with the occupations. In all categories, less than $20 \%$ of vacancies demand computer skills. Most commonly, they are required in administrative occupations (16\%). Paradoxically, the lowest explicit demand for computer skills among office and service occupations is in highly complex, professional occupations (7\%). The only non-office occupational group with nonnegligible demand for computer skills is crafts and trades workers (4\%).

\section{DISCUSSION AND CONCLUSIONS}

We review our findings from the three data sources in Tab. 4. What we see based on a comparison of tasks associated with individual occupations in the ISCO classification and contrasted with WI data is that while computer skills are typically necessary in particular for high-skill, professional occupations and only being rather useful for medium skill office/service occupations, nearly all workers in this category use a computer at work. Indeed, when looking at vacancy data, we see that oftentimes the explicit demand for computer skills is the highest among medium skill non-manual occupations, in particular service and sales. It appears that for high-skilled occupations, computer skills are assumed and taken for granted, by employers. Among the manual jobs holders, we see it is often the case that occupations, in which computers are rarely used, are limited to lowskill labor.
Our analysis shows the potential of web data as a source of information for scholars and professionals in need of information about the relevance of specific skills in the labor market. In particular, we show that web surveys can be used to explore computer skills applicability across detailed occupations. We also show, however, that there are limitations connected to using vacancy data. The main cause for concern is connected to the low incidence of explicit requirements for general computer skills even in some types of vacancies, where the use of such skills is clearly required to fulfil tasks associated with the respective occupations.

We show that computers have not only become nearly universal in almost any office job, but are increasingly common in manual occupations, too. Jobs not entailing any use of a computer appear increasingly concentrated in the low complexity, elementary occupations 
Tab. 4: Overview of computer skills applicability based on different data sources

\begin{tabular}{|c|c|c|c|}
\hline Skill level & $\begin{array}{l}\text { Computer skills requirements } \\
\text { inferred from tasks }\end{array}$ & $\begin{array}{l}\text { Job vacancy demand } \\
\text { for computer skills }\end{array}$ & $\begin{array}{l}\text { Use of computers reported } \\
\text { by occupation holders }\end{array}$ \\
\hline High & Useful, sometimes necessary & Medium & High \\
\hline Medium Office & Useful, sometimes necessary & Medium to high & High \\
\hline Medium Manual & Not needed, sometimes useful & Low & Medium \\
\hline Low & Not needed & Low & Low to medium \\
\hline
\end{tabular}

category. This represents a challenge particularly for older skilled workers lacking computer skills, who might be excluded from the labor market if not provided with appropriate IT training.

Looking at job vacancy data, we see that while for professional jobs, computer skills are not explicitly mentioned, which is likely due to expectation of employers that all candidates for some position are able to use computers, they are relatively often specified for administrative positions. Among skilled manual occupations, IT requirements appear to be often stressed for craft and trade workers. One way to interpret this finding is that in these occupations, there perhaps remains greater friction between the demand for computer skills and the supply of qualified candidates with those skills, incentivizing employers to stress the importance of computer proficiency as a requirement for employment.

Further research is needed to establish the link between explicit listing of a skill require- ment and expectation of it being instrumental for labor market matching. Nonetheless, there is a potential for an interesting synergy between the two web-based data sources: An online survey can be deployed to gain a detailed account of the computerization of work across occupations, while job vacancies can tell us where there is a particular risk of mismatch between job requirements and the skill of job candidates.

Given that WI is a continuous and international survey and that job vacancies are collected in an increasingly systematic fashion, it appears to be a suitable resource to explore the progress of computerization in time and across labor markets, potentially providing for a better understanding of the labor market matching and evidence-based policy in the areas of education and training. To fulfil this potential however, substantial work is needed to further explore the apparent limitations of online job sources and how they could be potentially countered.

\section{ACKNOWLEDGEMENT}

The authors are thankful to Textkernel, specifically Bauke Visser and Jakub Zavrel, for providing the job vacancy data. Further, we thank Alina Poliakova for assistance with coding IT skills requirements in individual occupations on the basis of tasks associated with them.
The authors gratefully acknowledge the financial support of the Eduworks Marie Curie Initial Training Network Project (PITN-GA2013-608311) of the European Commission's 7th Framework Program. 


\section{REFERENCES}

AcemoĞLu, D. and Autor, D. 2011. Skills, Tasks and Technologies: Implications for Employment and Earnings. In Ashenfelter, O. and CARD, D. (eds.). Handbook of Labor Economics, Volume 4, Part B, Chapter 12, pp. 1043-1171. DOI: $10.1016 /$ S0169-7218(11)02410-5.

Askitas, N. and Zimmermann, K. F. 2015. The Internet as a Data Source for Advancement in Social Sciences. International Journal of Manpower, 36 (1), 2-12.

DOI: 10.1108/IJM-02-2015-0029.

Autor, D. H. 2001. Wiring the Labor Market. Journal of Economic Perspectives, 15 (1), 25-40. DOI: $10.1257 /$ jep.15.1.25.

BArley, S. R. and Tolbert, P. S. 1991. Introduction: At the Intersection of Organizations and Occupations. In Tolbert, P. S. and Barley, S. R. (eds.). Research in the Sociology of Organizations, Vol. 8, pp. 1-13.

Beblavý, M., AkgüÇ, M., Fabo, B. and Lenaerts, K. 2016a. What Are the New Occupations and the New Skills? And How are They Measured? InGRID Working Paper. DOI: 10.5281/zenodo.1882280.

Beblavý, M., Fabo, B. and Lenaerts, K. 2016b. Demand for Digital Skills in the US Labor Market: The IT Skills Pyramid. CEPS Special Report No. 154.

Beblavý, M., Fabo, B. and Lenaerts, K. 2016c. Skills Requirements for the 30 Most-Frequently Advertised Occupations in the United States: An Analysis Based on Online Vacancy Data. CEPS Special Report No. 11406.

Beblavý, M., Mýtna Kureková, L. and Haita, C. 2016d. The Surprisingly Exclusive Nature of Medium- and Low-skilled Jobs: Evidence from a Slovak Job Portal. Personnel Review, 45 (2), 255-273. DOI: 10.1108/PR-12-2014-0276.

Becker, G. S. 1962. Investment in Human Capital: A Theoretical Analysis. Journal of Political Economy, 70 (5), 9-49. DOI: 10.1086/258724.

Benhabib, J. and Spiegel, M. M. 1994. The Role of Human Capital in Economic Development Evidence from Aggregate Cross-Country Data. Journal of Monetary Economics, 34 (2), 143-173. DOI: 10.1016/0304-3932(94)90047-7.

BGT. 2015. Crunched by the Numbers: Digital Skills Gap in the Workforce. Burning Glass Technologies Report.
Bührer, C. and Hagist, C. 2017. The Effect of Digitalization on the Labor Market. In Ellermann, H., Kreutter, P. and Messner, W. (eds.). The Palgrave Handbook of Managing Continuous Business Transformation, pp. 115-137. DOI: 10.1057/978-1-137-60228-2_5.

CEDEFOP. 2015. Skill Shortages and Gaps in European Enterprises: Striking a Balance Between Vocational Education and Training and the Labour Market Cedefop Reference Series No. 102. DOI: $10.2801 / 042499$.

CEDEFOP. 2014. Skill Mismatch: More than Meets the Eye. Briefing Note. DOI: 10.2801/57022.

Cowen, T. 2013. Average Is Over: Powering America Beyond the Age of the Great Stagnation. Dutton.

Crosby, O. 2002. New and Emerging Occupations. Occupational Outlook Quarterly, 46 (3), 16-25.

DAmARIN, A. K. 2006. Rethinking Occupational Structure: The Case of Web Site Production Work. Work and Occupations, 33 (4), 429-463. DOI: $10.1177 / 0730888406293917$.

Drahokoupil, J. and Fabo, B. 2020. The Limits of Foreign-Led Growth: Demand for Skills by Foreign and Domestic Firms. Review of International Political Economy. DOI: 10.1080/09692290.2020.1802323.

Elias, P. 1997. Occupational Classification (ISCO-88): Concepts, Methods, Reliability, Validity and Cross-National Comparability. OECD Labour Market and Social Policy Occasional Paper No. 20. DOI: $10.1787 / 304441717388$.

Eurostat. 2010. Employers' Perception of Graduate Employability. Analytical report. Flash Eurobarometer No. 304.

FABO, B. 2017. Towards an Understanding of Job Matching Using Web Data. CentER Dissertation Series No. 528. Tilburg University.

Fabo, B., Beblavý, M. and Lenaerts, K. 2017. The Importance of Foreign Language Skills in the Labour Markets of Central and Eastern Europe: Assessment Based on Data from Online Job Portals. Empirica, 44 (3), 487-508. DOI: $10.1007 / \mathrm{s} 10663-017-9374-6$.

Fabo, B. and Kahanec, M. 2018. Can a Voluntary Web Survey be Useful Beyond Explorative Research? International Journal of Social Research Methodology, 21 (5), 591-601. DOI: $10.1080 / 13645579.2018 .1454639$.

FABo, B. and TiJdens, K. 2014. Using Web Data to Measure the Demand for Skills. CELSI Discussion Paper No. 21. 
Horrigan, J. B. 2016. Lifelong Learning and Technology. Pew Research Center, Internet \& Technology.

Hunter, D. 2009. ISCO-08 Draft Definitions. ILO, Geneva.

Lenaerts, K., Beblavý, M. and Fabo, B. 2016. Prospects for Utilisation of Non-Vacancy Internet Data in Labor Market Analysis - An Overview. IZA Journal of Labor Economics, 5 (1), 1-18. DOI: $10.1186 / \mathrm{s} 40172-016-0042-\mathrm{z}$.

Levenson, A. and Zoghi, C. 2010. Occupations, Human Capital and Skills. Journal of Labor Research, 31 (4), 365-386.

DOI: $10.1007 / \mathrm{s} 12122-010-9098-\mathrm{x}$.

Mýtna Kureková, L., Beblavý, M., Haita, C. and Thum, A.-E. 2016. Employers' Skill Preferences across Europe: Between Cognitive and Non-Cognitive Skills. Journal of Education and Work, 29 (6), 662-687. DOI: $10.1080 / 13639080.2015 .1024641$.

MÝtna Kureková, L., Beblavý, M. and ThumThysen, A. 2015. Using Online Vacancies and Web Surveys to Analyse the Labour Market: a Methodological Inquiry. IZA Journal of Labor Economics, 4 (18), 1-20. DOI: 10.1186/s40172015-0034-4.

MÝtna Kureková, L., Haita, C. and Beblavý, M. 2013. Being and Becoming Low-Skilled: A Comprehensive Approach to Studying LowSkillness. NEUJOBS Working Paper No. 4.3.1. DOI: $10.2139 / \operatorname{ssrn} .2402734$.

Schultz, T. W. 1971. Investment in Human Capital: The Role of Education and of Research. New York: Free Press.

Smith, A. 2015. Searching for Work in the Digital Era. Pew Research Center, Internet \& Technology.

Steinmetz, S., Bianchi, A., Tijdens, K. and BiffignAnd, S. 2014. Improving Web Survey Quality: Potentials and Constraints of Propensity Score Adjustments. In Callegaro, M., Baker, R. P., Bethlehem, J., Göritz, A. S., Krosnick, J. A. and Lavrakas, P. J. (eds.). Online Panel Research: A Data Quality Perspective, Part IV, Chapter 12, pp. 273-298. John Wiley \& Sons.
Tijdens, K., Beblavý, M. and Thum-Thysen, A. 2018. Skill Mismatch Comparing Educational Requirements vs Attainments by Occupation. International Journal of Manpower, 39 (8), 996-1009. DOI: 10.1108/IJM-10-2018-0328.

Tijdens, K., De Ruijter, E. and De Ruijter, J. 2014. Comparing Tasks of 160 Occupations across Eight European Countries. Employee Relations, 36 (2), 110-127. DOI: 10.1108/ER-05-2013-0046.

Tijdens, K. and Steinmetz, S. 2016. Is the Web a Promising Tool for Data Collection in Developing Countries? An analysis of the Sample Bias of 10 Web and Face-to-Face Surveys from Africa, Asia, and South America. International Journal of Social Research Methodology, 19 (4), 461-479. DOI: 10.1080/13645579.2015.1035875.

Tijdens, K. and Visintin, S. 2016. What Do Workers Do? Measuring the Intensity and Market Value of Tasks in Jobs. AIAS Working Paper No. 161.

Tijdens, K. 2010. Measuring Occupations in WebSurveys: the WISCO Database of Occupations. AIAS Working Paper No. 10-86.

Visintin, S., Tijdens, K., Steinmetz, S. and de Pedraza, P. 2015. Task Implementation Heterogeneity and Wage Dispersion. IZA Journal of Labor Economics, 4 (20), 1-24. DOI: 10.1186/s40172-015-0036-2.

Winterton, J. 2009. Competence across Europe: Highest Common Factor or Lowest Common Denominator? Journal of European Industrial Training, 33 (8/9), 681-700. DOI: $10.1108 / 03090590910993571$.

Zavrel, J. 2016. Industry Strength Labor Market Web Mining. Keynote speech at the Eduworks Vacancy Mining and Analysis Workshop, Amsterdam, 24 March 2016.

\section{AUTHOR'S ADDRESS}

Brian Fabo, National Bank of Slovakia, Research Department, Imricha Karvaša 1, 81305 , Bratislava, Slovakia, e-mail: brian.fabo@nbs.sk

Martin Kahanec, Central European University, School Of Public Policy, Quellenstraße 51-55, 1100 Vienna, Austria, e-mail: KahanecM@spp.ceu.edu 